\title{
Avaliação do desenvolvimento de mudas nativas em uma área paludosa, no município de Inconfidentes, MG
}

Bruna Mélega Sarmento

Bruno Senna Corrêa

Laércio Loures ${ }^{3}$

Aloysio Souza de Moura ${ }^{4}$

\section{Resumo}

O presente trabalho trata-se da avaliação inicial do desenvolvimento de cem mudas nativas, durante onze meses, plantadas numa área paludosa na fazenda experimental do Instituto Federal de Educação Ciência e Tecnologia do Sul de Minas Gerais, Campus Inconfidentes, MG. As dez espécies nativas escolhidas para o plantio foram Nectandra nitidula (canelinha), Croton urucurana (sangra-d'água), Inga vera (ingá), Triplaris americana (pau-formiga), Alchornea glandulosa (tapiá), Erythrina falcata (moxoco), Cordia ecalyculata (café-de-bugre), Cedrela odorata (cedro-do-brejo), Acacia polyphylla (monjoleiro) e Citronella gongonha (laranjeira-do-brejo). Foram plantadas dez mudas de cada espécie, no espaçamento de 1,5 x 2,0 m, em setembro do ano de 2007. Foram feitas avaliações mensais até o mês de julho do ano de 2008. Os parâmetros utilizados nas avaliações foram: Altura (H), Diâmetro à Altura do Solo (DAS) e Diâmetro de Copa. Nas onze avaliações, esses parâmetros mostraram que as espécies apresentaram diferentes ritmos de desenvolvimento, em função da área ser permanentemente encharcada. As espécies que se destacaram em Altura, DAS e Diâmetro de Copa foram Citronella gongonha (laranjeira-do-brejo) e Cedrela odorata (cedro-do-brejo), significando que essas espécies são as mais propícias para o ambiente paludoso.

Palavras-chave: Matas de brejo. Crescimento vegetal. Espécies hidrófilas

\section{Introdução}

Pouco se conhece sobre as matas de brejo, também chamadas de matas paludosas ou higrófilas, que podem ser caracterizadas por um conjunto muito particular de espécies.

Por estarem estabelecidas sobre solos hidromórficos, estão sob influência de água superficial em caráter permanente.

Essas formações florestais são condicionadas por uma série de fatores físicos, tais como relevo, tipos de solos, altitude e clima. Ocorrem em várzeas, planícies de inundação, nascentes, margens de rios ou lagos, baixadas ou depressões, onde a saturação hídrica do solo é consequência do afloramento da água do lençol freático.

1 IFSULDEMINAS, campus Inconfidentes.

2 CEFET, MG, campus Nepomuceno/e-mail: bruno.senna@gmail.com

3 IFSULDEMINAS, campus Inconfidentes.

4 Mapinguari Consultoria Ambiental Ltda - Biólogo. 
As matas de brejo apresentam características florísticas, estruturais e fisionômicas intrínsecas ao seu ambiente. Nestes aspectos elas se diferem dos demais tipos de florestas, mesmo das matas ciliares periodicamente inundáveis. São florestas de alta densidade com árvores de porte menores. Essas matas são pouco estudadas no Brasil e em especial no sul de Minas Gerais.

0 referido trabalho foi desenvolvido com o objetivo de estudar o desenvolvimento de dez espécies arbóreas nativas numa área paludosa. Os resultados do trabalho poderão ampliar o conhecimento sobre a vegetação nativa do município de Inconfidentes e subsidiar projetos de recuperação de nascentes, de áreas brejosas e matas ciliares através da escolha de espécies comprovadamente tolerantes ao ambiente de solos extremamente encharcados.

\section{Revisão da literatura}

\section{1 Áreas de Preservação Permanente}

As Áreas de Preservação Permanente (APP) são áreas nas quais, por imposição da lei, a vegetação deve ser mantida intacta, tendo em vista que esta garante a preservação dos recursos hídricos, a estabilidade geológica e a biodiversidade, bem como o bem-estar das populações humanas (ARAÚJ0, 2002). Nessas áreas não se pode fazer a retirada da cobertura vegetal original, permitindo assim, que elas possam exercer, em plenitude, suas funções ambientais (SOARES et al., 2002).

0 regime de proteção das APPs é bastante rígido: a regra é a intocabilidade, sendo possível abolir essa regra, excepcionalmente, quando a supressão da vegetação é de utilidade pública ou de interesse social, legalmente prevista e aprovada através de um processo de licenciamento ambiental.

A Lei no 4.771 de 1965, Código Florestal, revogada pela Lei n 12.651 de 2012, apresenta dois tipos de APPs: as criadas pela própria lei e as por ela previstas, mas que demandam ato declaratório específico do Poder Público para sua criação. No seu art. $2^{\circ}$, fica estabelecido que:

Art. $2^{\circ}$ Consideram-se de preservação permanente, pelo só efeito desta Lei, as florestas e demais formas de vegetação natural situadas:a) ao longo dos rios ou de qualquer curso d'água desde o seu nível mais alto em faixa marginal cuja largura mínima será: 1 - de 30 (trinta) metros para os cursos d'água de menos de 10 (dez) metros de largura; 2 - de 50 (cinquenta) metros para os cursos d'água que tenham de 10 (dez) a 50 (cinquenta) metros de largura; 3 - de 100 (cem) metros para os cursos d'água que tenham de 50 (cinquenta) a 200 (duzentos) metros de largura; 4 - de 200 (duzentos) metros para os cursos d'água que tenham de 200 (duzentos) a 600 (seiscentos)metros de largura; 5 - de 500 (quinhentos) metros para os cursos d'água que tenham largura superior a 600 (seiscentos)metros; b) ao redor das lagoas, lagos ou reservatórios d'água naturais ou artificiais; c) nas nascentes, ainda que intermitentes e nos chamados "olhos d'água", qualquer que seja a sua situação topográfica, num raio mínimo de 50 (cinquenta) metros de largura; d) no topo de morros, montes, montanhas e serras; e) nas encostas ou partes destas, com declividade superior a $45^{\circ}$, equivalente a $100 \%$ na linha de maior declive; f) nas restingas, como fixadoras de dunas ou estabilizadoras de mangues; g) nas bordas dos tabuleiros ou chapadas, a partir da linha de ruptura do relevo, em faixa nunca inferior a 100 (cem) metros em projeções horizontais; $h$ ) em altitude superior a 1.800 (mil e oitocentos) metros, qualquer que seja a vegetação. 


\subsection{Nascentes}

Segundo Castro (1999) e Castro e Gomes (2001), as nascentes também são chamadas de mina, fio d'água, cabeceira, fonte e olho d'água, sendo aberturas naturais na superfície do terreno, de onde as águas subterrâneas escoam naturalmente. As nascentes localizam-se em encostas ou depressões do terreno ou ainda no nível de base representado pelo curso d'água local; podendo ser perenes (de fluxo contínuo), temporárias (de fluxo apenas na estação chuvosa) e efêmeras (surgem durante a chuva, permanecendo por apenas alguns dias ou horas) (CALHEIROS et al. 2004).

De acordo com Ladslau (2008), para a proteção e recuperação das nascentes, deve-se tomar algumas providências, como impedir ou limitar o acesso de animais com a construção de cercas, sendo esta prática suficiente para promover a regeneração da vegetação nativa. Outra medida importante é associar métodos de controle de erosão como plantio direto, terraceamento, curvas de nível, entre outros.

\subsection{Matas ciliares}

Segundo Oliveira Filho (1994), as matas ciliares são formações vegetais do tipo florestal, associadas aos corpos d'águas, podendo se estender por dezenas de metros a partir das margens e apresentar marcantes variações na composição florística e na estrutura comunitária, dependendo das interações que se estabelecem entre o ecossistema aquático e sua vizinhança.

As matas ciliares são os ecossistemas mais intensamente utilizados e degradados pelo homem, por possuírem solos férteis e úmidos, ideais para a agricultura, por fornecerem madeira, por apresentarem condições adequadas para construção de estradas e, principalmente nas regiões montanhosas, por exploração de areia e cascalho e, devido à sua beleza cênica, serem intensamente utilizadas para urbanização e recreação (BOTELHO; DAVIDE, 2002). As matas ciliares apresentam vital importância na proteção de mananciais, controlando a chegada de nutrientes, sedimentos, adubos e agrotóxicos e o processo de erosão das ribanceiras que provocará assoreamento de mananciais, influindo também nas características físicas, químicas e biológicas dos corpos de água e principalmente na qualidade da água (DAVIDE; BOTELHO, 1999).

De acordo com Botelho e Davide (2002), os principais benefícios das matas ciliares são:

a) manutenção da qualidade e quantidade da água pela função de tamponamento entre os cursos d'água e as áreas adjacentes cultivadas, retendo grande quantidade de sedimentos, defensivos agrícolas e nutrientes, e pela sua capacidade de proteção do solo contra os processos erosivos e aumento na capacidade de infiltração de água no solo;

b) estabilização das margens dos rios através da grande malha de raízes que dá estabilidade aos barrancos e atuação da serrapilheira, retendo e absorvendo o escoamento superficial, evitando o assoreamento dos leitos dos rios e das nascentes;

c) habitat para a fauna silvestre, proporcionando ambiente com água, alimento e abrigo para um grande número de espécies de pássaros e pequenos animais, além de funcionarem como corredores de fauna entre fragmentos florestais;

d) habitat aquático, promovendo sombreamento nos cursos d'água, abrigo, alimento e condição para reprodução e sobrevivência aos insetos, anfíbios, crustáceos e pequenos peixes.

\subsection{Importância das matas de brejo}

As florestas ripárias ou ripícolas, mais conhecidas como matas de brejo, são formações vegetais extremamente importantes em termos ecológicos, sendo essenciais para a manutenção da qualidade da água dos rios e da fauna ictiológica (CESP, 1987). Segundo Redford e Fonseca (1986), essas florestas são, também, essenciais para a sobrevivência da fauna de mamíferos das regiões do 
cerrado e da caatinga, provendo refúgio, água e alimento, funcionando também como corredores de penetração no cerrado para espécies de animais provenientes da Floresta Amazônica e Mata Atlântica, levando a uma importante permuta genética (fluxo gênico).

As matas de brejo restringem-se às áreas de várzeas ou planícies de inundação, em terrenos baixos, mais ou menos planos, que se encontram junto às nascentes ou em situações bem definidas nas margens dos rios, lagos ou depressões naturais (IVANAUSKAS; RODRIGUES; NAVE, 1997). Nestes locais ocorrem solos hidromórficos (Organossolos, Gleissolos, Plintossolos, etc.), apresentam baixa diversidade e são naturalmente fragmentadas de acordo com Leitão Filho (1982). Nas regiões de altitude, elas podem ser ainda semidecíduas e se apresentar com muitas árvores perfilhadas e inclinadas (LOURES, 2006).

De acordo com Rodrigues e Nave (2000), ocorre heterogeneidade florística e estrutural dentro e entre fragmentos, cujos motivos são poucos conhecidos, mas devem estar relacionados com variações ambientais, tais como cotas, topografia, altitude, fertilidade, textura do solo, drenagem, clima e perturbações do passado. As matas de brejo se diferenciam das florestas ciliares (áreas aluviais) por estarem sujeitas à presença de água no solo em caráter quase permanente. Essa umidade do solo contribui para a seletividade das espécies, ocorrentes nesta formação, relacionadas à adaptabilidade fisiológica das mesmas para resistir à saturação hídrica. De acordo com Marques (1994), seriam florestas ciliares com características florísticas e edáficas próprias.

As espécies encontradas nas matas de brejo podem ser incluídas em dois grupos: as peculiares, que são características desse ecossistema e não ocorrem em locais mais secos, e as complementares, que podem aparecer nos brejos, mas ocorrem preferencialmente em áreas com encharcamento temporário do solo, como as matas ciliares, também conhecidas como ripárias ou de galeria, e até em florestas mais secas, onde nunca ocorre o encharcamento do solo. As espécies peculiares são da maior importância para identificar as florestas de brejo, já que a sua ocorrência é característica deste tipo de ambiente. No entanto, algumas dessas espécies peculiares podem ser encontradas em áreas um pouco mais secas, com encharcamento periódico do solo, compartilhando o ambiente com as espécies complementares. De forma geral, as florestas de brejo representam um tipo de vegetação de grande relevância pela sua ocorrência em ambientes com baixa oxigenação do solo, dada pelo encharcamento permanente dessas áreas (TORRES et al., 1992).

As espécies generalistas e de solo drenado aumentam a riqueza da floresta, as espécies de solo encharcado são importantes principalmente na definição da dominância e densidade (MARQUES et al., 2003). De acordo com alguns autores (LIEBERG; JOLY, 1993; LOBO; JOLY, 1998; LOBO-FARIA, 1998; MARQUES; JOLY, 2000; PIMENTA et al., 1998) nas espécies de áreas paludosas ocorrem ajustes envolvendo o metabolismo respiratório das raízes, a germinação, a fenologia e a morfologia de raízes e caules condicionam a ocorrência do número reduzido dessas espécies. Segundo Marques (1994), as florestas de brejo estão gradativamente desaparecendo, sem que se conheçam suas características ecológicas e a sua importância na proteção dos mananciais.

\section{Material e métodos}

\subsection{Caracterização da área de estudo}

O presente trabalho foi desenvolvido em uma área de floresta paludosa (VELOSO, 1991) localizada na fazenda experimental do Instituto Federal de Educação, Ciência e Tecnologia do Sul de Minas Gerais, Campus Inconfidentes, na região sul de Minas Gerais, entre as coordenadas $22^{\circ} 19^{\prime} 01^{\prime \prime S}$ e 46¹9'40"W, no município de Inconfidentes.

A área de estudo é constituída por solo hidromórfico, ou seja, encharcado durante todo o ano, 
a altitude média do local é $910 \mathrm{~m}$ e a temperatura média anual do município é $19,2^{\circ} \mathrm{C}$. 0 clima da região em que se encontra o município, segundo a classificação de Köppen (1948), é tropical de altitude Cwb, ou seja, detém um clima temperado em que as estações de verão e inverno são bem definidas, as chuvas concentram-se durante o verão, assim, a precipitação média anual está entorno de $1744,2 \mathrm{~mm}$ e com temperaturas que variam de $34^{\circ} \mathrm{C}$, no verão, a $-2^{\circ} \mathrm{C}$, no inverno (INCONFIDENTES, 2007).

O terreno que contorna a área paludosa mede $200 \mathrm{~m}^{2}$, e se localiza do lado dos tanques de piscicultura da fazenda experimental do Instituto Federal de Educação Ciência e Tecnologia do Sul de Minas Gerais, Campus Inconfidentes (Figura 1).

A vegetação regional é de Mata Atlântica classificada como: estacional montana semidecídua.

Figura 1. Área paludosa do estudo.

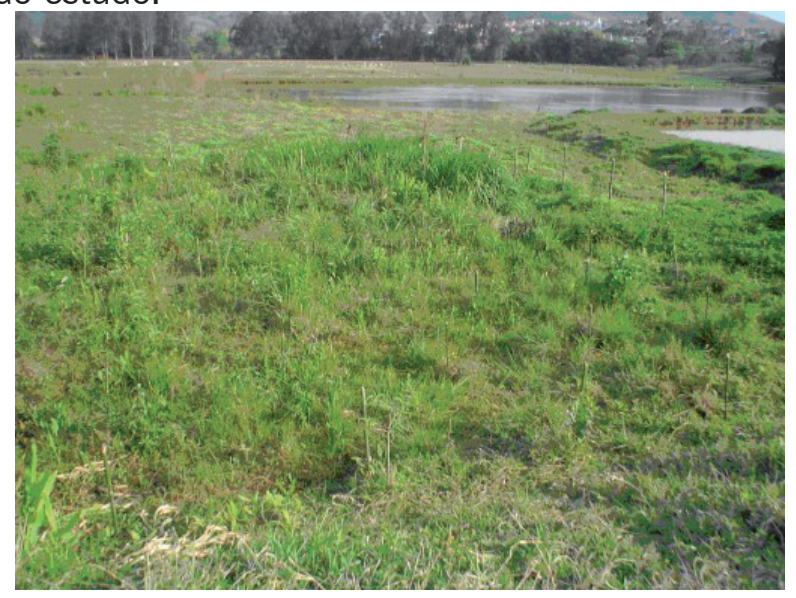

Fonte: Elaboração própria.

\subsection{Método}

\section{Seleção das Espécies}

As espécies arbóreas foram selecionadas pelo fato de que nesta região ocorrem muitas áreas paludosas em planícies do entorno de riachos, principalmente nas depressões do relevo ondulado da mesma, e em pequenas áreas de nascentes difusas. Por ser área paludosa, valorizada pelo pastoreio em função de sua umidade, houve um intenso desmatamento dessas áreas no passado, havendo então, nos dias de hoje, a necessidade de procura para recuperação e vegetação florestal neste ambiente. As espécies selecionadas para a avaliação de seu desenvolvimento são nativas, pioneiras e secundárias iniciais ou tardias, de acordo com a Tabela 1, e foram fornecidas pelo viveiro de mudas do Instituto Federal de Educação, Ciência e Tecnologia do Sul de Minas Gerais, campus Inconfidentes. 
Tabela 1. Nomes científicos, nomes populares, famílias e grupos ecológicos das espécies plantadas no experimento.

\begin{tabular}{cccc}
\hline Nome Científico & Nome Popular & Família & Grupo Ecológico \\
\hline Acácia polyphylla & Monjoleiro & Fabaceae Mimosoideae & Secundária Inicial \\
Alchornea glandulosa & Tapiá & Euphorbiaceae & Pioneira \\
Cedrela odorata & cedro-do-brejo & Meliaceae & Secundária tardia \\
Citronella gongonha & laranjeira-do-brejo & Cardiopteridaceae & Secundária inicial \\
Cordia ecalyculata & café-de-bugre & Boraginaceae & Secundária inicial \\
Croton urucurana & sangra-d'água & Euphorbiaceae & Pioneira \\
Erythrina falcata & Moxoco & Fabaceae Faboideae & Pioneira \\
Inga vera & Ingá & Fabaceae Mimosoideae & Secundária inicial \\
Nectandra nitidula & Canelinha & Lauraceae & Secundária inicial \\
Triplaris americana & pau-formiga & Polygonaceae & Secundária Inicial \\
\hline
\end{tabular}

Fonte: Lorenzi, H., 2002; Loures, L., 2008 (comunicação pessoal); Souza; Lorenzi (2005), Baseado em APG II, 2005).

\section{Preparo do solo}

Para o preparo do solo não foi utilizado nenhum tipo de adubação, correções químicas nem controle de formigas cortadeiras.

\section{Plantio}

O plantio foi realizado no mês de setembro do ano de 2007. Para o coveamento, por se tratar de solo hidromórfico, de pouca consistência, foi utilizada uma haste de madeira de $10(\mathrm{dez}) \mathrm{cm}$, apontada, para a perfuração do solo, cuja abertura serviu de covas para o plantio das mudas. As plantas, em seguida, foram marcadas com estacas de bambu (Figura 2).

No plantio, o espaçamento adotado foi o de $1,5 \mathrm{~m}$ na linha e 2,0m nas entrelinhas, caracterizando o espaçamento de $1,5 \mathrm{~m} \times 2,0 \mathrm{~m}$.

\section{Tratos Culturais}

Foram feitas roçadas de dois em dois meses com uma roçadeira costal, de motor a combustão, para diminuir a competição das espécies invasoras, com destaque à espécie braquiária-de-cipó (Brachiaria subquadripara), que apresenta grande agressividade nas condições de alagamento. Não foi feito coroamento, para manter a estabilidade do solo e evitar o empoçamento de água em torno das mudas, fazendo com que as mesmas não ficassem bambas, tombassem e morressem. 


\section{Parâmetros de avaliação das mudas}

Na avaliação do desenvolvimento das plantas na área paludosa foram usados os seguintes parâmetros morfológicos:

a) Altura $(\mathrm{H})$ : medida da altura do colo ao ápice principal das mudas, utilizando a fita métrica, com medições mensais (Figura 3);

b) Diâmetro altura do solo (DAS): medida do diâmetro rente ao solo, utilizando o aparelho paquímetro, com medições mensais (Figura 4);

c) Diâmetro de copa (DC): Medida do raio da copa das mudas, por meio das médias de duas medições dos dois lados da copa, utilizando a fita métrica, com medições mensais (Figura 5).

A avaliação do desenvolvimento das mudas plantadas, por meio dos parâmetros acima mencionados, iniciou-se no mesmo mês do plantio, totalizando 11 (onze) meses de avaliações, desde o mês de setembro de 2007 até o mês de julho de 2008.

Para analisar os resultados das avaliações dos parâmetros acima mencionados, foram utilizados gráficos gerados pelo programa SigmaPlot2000.

Figura 2. Plantio com utilização de estacas para identificação das mudas.

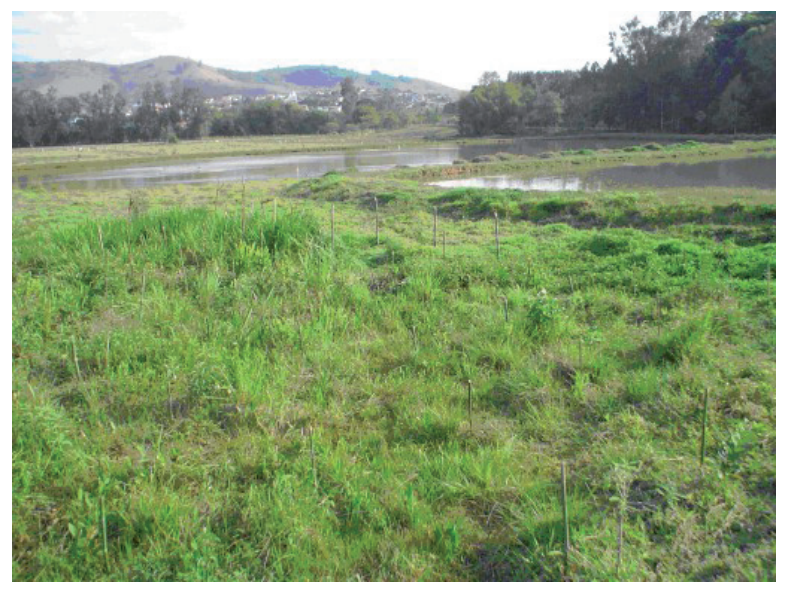

Fonte: Elaboração própria.

Figura 3. Avaliação da altura da planta Nectandra nitidula (canelinha).

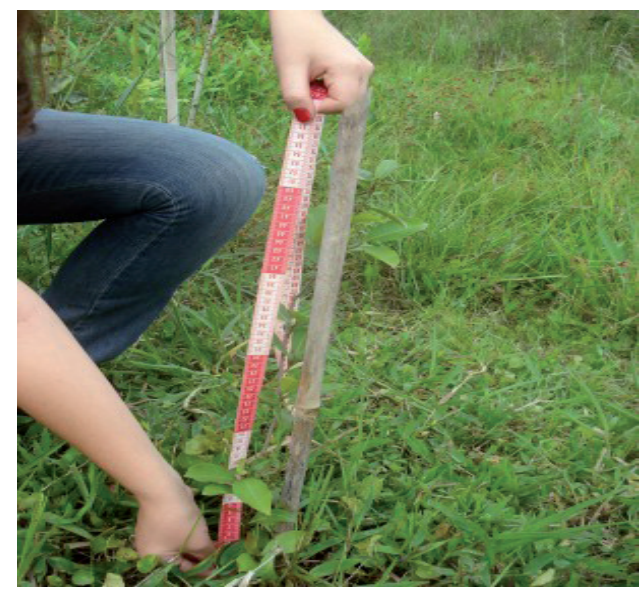

Fonte: Elaboração própria. 
Figura 4. Avaliação do DAS de Croton urucurana (sangra-d'água).

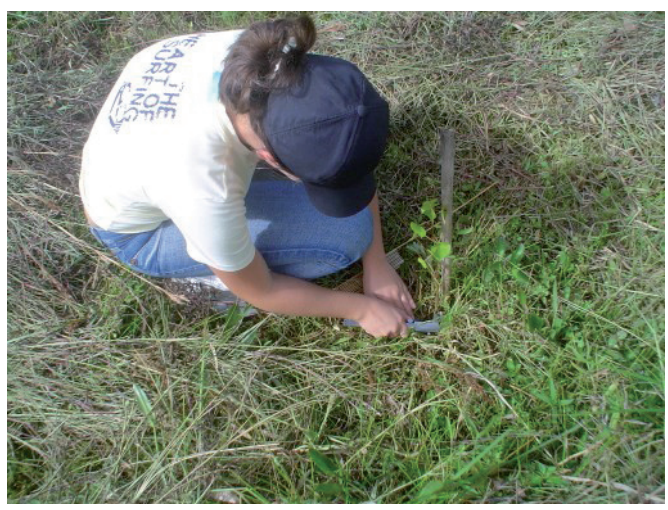

Fonte: Elaboração própria.

Figura 5. Avaliação do diâmetro de copa de Erythrina falcata (moxoco).

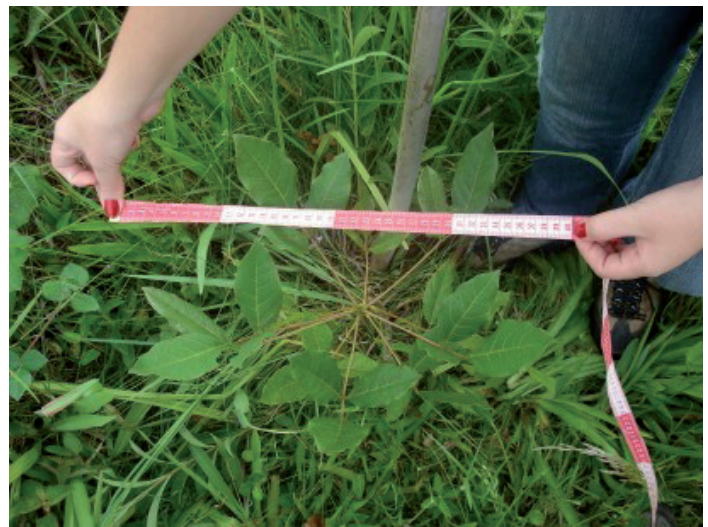

Fonte: Elaboração própria.

\section{Resultados e discussão}

\subsection{Sobrevivência das espécies}

Das 100 mudas plantadas na área paludosa, 52 mudas, ou seja, 52\% morreram durante os onze meses de avaliações. Essa taxa de mortalidade mostra que algumas espécies apresentaram dificuldades de adaptação no ambiente permanentemente encharcado.

As espécies que apresentaram o maior índice de mortalidade foram a A. polyphylla (monjoleiro, 100\%), l. vera (ingá, 90\%), a T. americana (pau-formiga, 80\%) e a A. glandulosa (tapiá, 70\%).

A espécie A. polyphylla (monjoleiro), desenvolveu-se até o décimo mês de avaliação, mas na décima primeira avaliação todas suas mudas estavam mortas, significando que a mesma não conseguiu tolerar mais a área paludosa. Esta alta taxa de mortalidade pode também estar relacionada às questões intrínsecas e fisiológicas da espécie, pois, o mês em que as mudas morreram foi julho, que coincidiu com o inverno, o que poderia ter ocorrido com a espécie é a não tolerância à baixa 
temperatura da água no solo. A mortalidade de algumas mudas, plantadas na última linha do plantio, também pode ter ocorrido pelo fato de que houve competição com a espécie braquiária-de-cipó (Brachiaria subquadripara), que invadiu uma parte da área onde havia fluxo de água de um tanque de peixes à montante, cuja água apresentava altas concentrações de nutrientes oriundos de detritos dos peixes de engorda, favorecendo o crescimento desta espécie invasora e agressiva (CARBONARI; MARTINS; TERRA, 2003). Também pode ter sido pelo fato de um possível ataque de formigas cortadeiras (Acromyrmex spp.) em algumas mudas, que vieram da vegetação vizinha. Segundo Silva (2007), esta espécie foi encontrada em um componente arbóreo de fragmentos de floresta aluvial temporariamente inundável em São João da Bela Vista, MG, e em baixa densidade em um fragmento paludoso de floresta ripária em Coqueiral, MG (ROCHA et al.,2005), corroborando os resultados do estudo que indicam que esta espécie não é tolerante a solos permanentemente encharcados.

A taxa de mortalidade da espécie I. vera (ingá) foi alta, (90\%), isso devido à planta possuir mais afinidade com áreas aluviais, temporariamente inundáveis, e também crescer em terrenos drenados (LORENZI, 2002). Num estudo de Rodrigues et al. (2003), em Luminárias, MG, a espécie foi constatada numa floresta que contém representações de floresta estacional semidecidual aluvial e floresta estacional semidecidual montana. A espécie também foi encontrada em um fragmento de floresta estacional decidual aluvial no baixo Rio Jacuí, em Cachoeira do Sul, RS, (ARAÚJO et al., 2004), coincidindo com o estudo de Budke et al. (2004), onde a espécie foi encontrada em baixa densidade em uma área de floresta ribeirinha do arroio Passo das Tropas, em Santa Maria, RS, justificando que esta espécie é tolerante a solos temporariamente e não permanentemente inundáveis.

A espécie T. americana (pau-formiga) apresentou uma alta taxa de mortalidade (80\%), que pode ser justificada pelo fato de haver competição entre a espécie braquiária-de-cipó ( $B$. subquadripara) com algumas mudas da espécie, e também pode ter ocorrido um possível ataque de formigas cortadeiras (Acromyrmex spp.), vindas da vegetação vizinha, que invadiram uma parte da área. Segundo Lorenzi (2002), esta espécie apresenta preferência por solos muito úmidos ou até alagadiços. De acordo com o estudo feito por Maximiano (2008), a espécie foi uma das que melhor se adaptaram numa área no entorno de uma nascente pontual com solo drenado no município de Inconfidentes, MG.

A taxa de mortalidade de $A$. glandulosa (tapiá) (70\%), mostrou que a espécie não foi muito tolerante à área encharcada. De acordo com Lorenzi (2002), esta espécie é frequente nas formações secundárias como capoeiras e capoeirões, ocorrendo também em matas primárias, principalmente em beiradas e clareiras. Nos estudos de Teixeira e Assis (2005) e de Rocha et al. (2005), esta espécie foi encontrada em baixa densidade numa floresta paludosa em Rio Claro, SP, e também numa floresta ripária em Coqueiral, MG. Tais condições diferem das apresentadas no ambiente de implantação do estudo, ou seja, área paludosa, podendo ser justificada que a espécie é tolerante a solos temporariamente encharcados.

As espécies que toleraram e se adaptaram melhor à área paludosa, apresentando percentagem decrescente de mortalidade, foram a C. urucurana (sangra-d'água, 20\%), C. gongonha (laranjeira-do-brejo, 20\%), N. nitidula (canelinha, 30\%), C. ecalyculata (café-de-bugre, 30\%), E. falcata (moxoco, 40\%) e C. odorata (cedro-do-brejo, 40\%).

A mortalidade de algumas mudas destas espécies pode estar relacionada ao fato de que essas mudas estavam plantadas próximas ao limite da área, onde ocorreu uma grande concentração da espécie braquiária-de-cipó ( $B$. subquadripara), localizada na área adjacente à área de estudo, onde pode ter ocorrido competição entre as espécies, pois, a braquiária-de-cipó apresenta-se como espécie pioneira exigente de luz com grande agressividade, sendo uma planta invasora (CARBONARI et al., 2003).

Estudos realizados em áreas paludosas, matas de brejo e florestas ripárias (TORRES et al., 1992; TONIATO et al., 1998; LOURES, 2006; BOTELHO; Davide, 2002 e FERREIRA et al., 2007a) 
apontam que as espécies mais indicadas para este tipo de ambiente são $C$. odorata, $C$. gongonha, $E$. falcata, C. urucurana e $N$. nitidula, corroborando os resultados obtidos neste estudo.

\subsection{Desenvolvimento das espécies em altura $(\mathrm{H})$}

De acordo com a Figura 6, as espécies que mais se destacaram em altura ao longo dos 11 (onze) meses de avaliação foram C. gongonha (laranjeira-do-brejo), C. odorata (cedro-do-brejo) e C. urucurana (sangra-d'água).

Figura 6. Desenvolvimento das espécies em altura $(\mathrm{H})$, ao longo das onze avaliações.

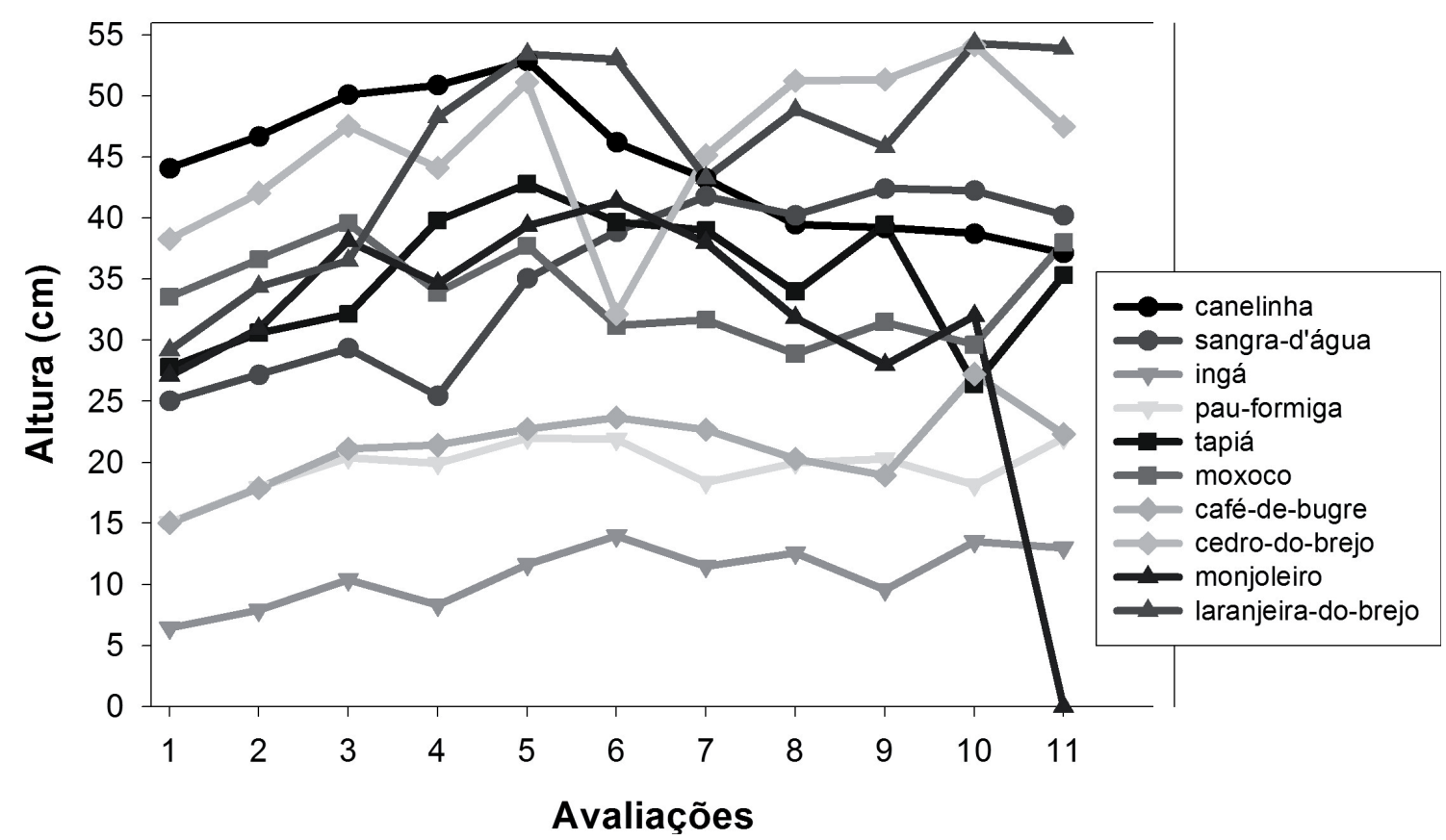

Fonte: Elaboração própria.

A espécie C. gongonha (laranjeira-do-brejo), no estudo de Loures et al, (2007), foi uma das espécies com maior número de indivíduos com destaque em altura e maior valor de importância neste tipo de floresta. Em Loures (2006), a espécie obteve alta densidade na floresta paludosa. Segundo Teixeira e Assis (2005), a espécie foi encontrada numa floresta paludosa em Rio Claro, SP, podendo-se inferir que esta espécie tem significativa tolerância às áreas paludosas.

A espécie C. odorata (cedro-do-brejo), no estudo realizado por Toniato et al. (1998), em Análise Fitossociológica de Remanescente de Mata de Brejo, foi a que mais se destacou em altura. Segundo estudos de Cruz et al. (2003) e Lobo et al. (2007), esta é uma espécie recomendada para recuperação de matas ciliares. Em Maximiano (2008), a espécie foi umas das que melhor se adaptaram em uma área de nascente pontual com solo drenado, e em Teixeira e Assis (2005), foi encontrado alto número de indivíduos em uma floresta paludosa em Rio Claro, SP, significando que a espécie pode tolerar ambientes paludosos.

A espécie $C$. urucurana (sangra-d'água), segundo Morais et al. (2007), foi comum em dois ou mais fragmentos de mata ciliar semidecidual no Alto São Francisco, apresentando densidade absoluta máxima. Assim como no estudo de Davide et al. (1996), "Comportamento de espécies florestais 
de mata ciliar em área de depleção num reservatório na usina hidrelétrica de Camargos, Itutinga, MG", a espécie apresentou altas taxas de sobrevivência nessas áreas. No estudo de Teixeira e Assis (2005), a espécie foi encontrada com baixa densidade em uma floresta paludosa de Rio Claro, SP. Significando que a espécie tem mais tolerância e melhor desenvolvimento em áreas ciliares, onde o solo é temporariamente encharcado.

As espécies que apresentaram menor desenvolvimento em altura foram I. vera, (ingá), T. americana, (pau-formiga) e C. ecalyculata (café-de-bugre).

O baixo crescimento da espécie Inga vera pode ter ocorrido em função da espécie ser ocorrente em áreas inundadas periodicamente (Lobo et al., 2007). Segundo Cruz et al. (2003), esta espécie é indicada para recuperação de matas ciliares de beira de rios. Segundo Morais et al. (2007), a espécie é indicada para matas ciliares semideciduais. Segundo Vilela et al. (2000), a espécie apresentou o maior número de indivíduos, maior índice de valor de importância na floresta aluvial e na encosta da floresta ripária da cidade de Madre de Deus de Minas, MG. Segundo Araújo et al. (2004), esta é uma espécie adaptada ao ambiente aluvial. Pelo citado, ela é propícia para áreas de terras firmes de beira de rios e não para áreas brejosas.

A espécie T. americana (pau-formiga), segundo Cielo Filho e Santin (2002), obteve densidade relativa elevada em um fragmento florestal urbano com baixo teor de umidade do solo em Campinas, SP. Já Lorenzi (2002), diz que a espécie é característica de matas ciliares, e Maximiano (2008) diz que a espécie foi a que melhor se adaptou à área de nascente pontual. Isto significa que esta espécie tem boa tolerância a solos aluviais, ou seja, temporariamente encharcados como matas ciliares de beiras de rios.

O baixo crescimento da espécie $C$. ecalyculata (café-de-bugre) pode estar relacionado à sua intolerância a solos extremamente encharcados. Segundo Lorenzi (2002), esta espécie é típica de solos úmidos temporariamente inundados. No estudo de Meyer et al. (2004), esta espécie foi encontrada numa floresta de galeria em Belo Horizonte, MG. Em estudo de Araújo et al. (2004), a espécie foi encontrada num fragmento de floresta estacional decidual aluvial, temporariamente inundável em Cachoeira do Sul, RS. Hardt et al. (2006) indicam a espécie para reflorestamentos em matas ciliares. Pelos citados, pode-se justificar que esta espécie é tolerante em áreas aluviais de matas ciliares, temporariamente encharcadas.

$O$ restante das espécies tiveram crescimentos intermediários. As espécies $A$. glandulosa (tapiá), E. falcata (moxoco), N. nitidula (canelinha) e A. polyphylla (monjoleiro) se incluíram nesse intervalo.

A espécie $A$. glandulosa (tapiá), segundo Toniato et al. (1998), não é indicada para plantio em áreas de solo permanentemente encharcado, pois, é característica de solos aluviais da floresta pluvial atlântica (LORENZI, 2002). Segundo Vilela et al. (2000), esta espécie foi amostrada numa floresta estacional semidecidual montana aluvial e na encosta da floresta ripária, em Madre de Deus de Minas, MG. Segundo Gomes, Fish e Mantovani (2005), a espécie foi amostrada com alta dominância numa floresta pluvial tropical atlântica, em Pindamonhangaba, SP. Em Rocha et al. (2005), a espécie foi encontrada em baixíssima densidade em um habitat de encosta de uma floresta ripária permanentemente encharcada em Coqueiral, SP. Concordando com os resultados obtidos no estudo em questão.

A espécie E. falcata (moxoco), segundo Loures et al. (2007), foi amostrada numa floresta estacional semidecidual montana ribeirinha. Lorenzi (2002) sugere que o tipo de crescimento dessa espécie, em áreas de encharcamento temporário, é favorável a sua utilização em recuperação de áreas ciliares. Em Silva (2007), a espécie foi encontrada em uma fragmento de floresta aluvial no município de São Sebastião da Bela Vista, em MG. Em Maximiano (2008), a espécie se destacou em altura numa área de nascente pontual, com solo drenado, em Inconfidentes, MG, o que pode justificar o fato de algumas mudas da espécie não terem tolerado a área paludosa do estudo.

A espécie N. nitidula (canelinha), segundo Loures et al. (2007), ocorreu no sub-bosque, em uma floresta estacional semidecidual montana ribeirinha, na região de Santa Rita de Caldas, MG. Tal 
desenvolvimento sugere que a espécie não é indicada para solos permanentemente encharcados em sua fase inicial. Segundo Lorenzi (2002), é exclusiva de matas de galeria de regiões de altitude, ela ocorre preferencialmente em capoeiras e capoeirões situados em beira de rios de terrenos arenosos. Segundo Ferreira, Ferreira e Botelho (2007b), a espécie foi a segunda com maior valor de importância e teve ocorrência em um remanescente de mata próximo a uma nascente com elevada densidade dos indivíduos arbóreos, sendo grande fonte de propágulos. Segundo Pinto et al. (2005), a espécie é considerada generalista para o ambiente de nascentes, onde pode ser utilizada com sucesso, significando que esta espécie também é tolerante a solos temporariamente inundados.

A espécie A. polyphylla (monjoleiro) mostrou que não teve tolerância nem um bom desenvolvimento na área paludosa. No estudo de Rocha et al. (2005), a espécie ocorreu em baixa densidade numa floresta ripária em Coqueiral, SP. Já no estudo de Silva (2007), a espécie foi encontrada em fragmentos de floresta aluvial, temporariamente encharcadas, no município de São Sebastião da Bela Vista. O estudo de Maximiano (2008) mostrou que a espécie foi uma das que melhor se adaptaram à área de nascente pontual, com relevo declivoso e solo drenado em Inconfidentes, MG. Segundo Lorenzi (2002), sua distribuição é ampla em encostas e topos de morros de terrenos pedregosos e secos. Pode ser justificado que esta espécie é tolerante a solos aluviais, de matas ciliares e nascentes.

\subsection{Desenvolvimento das espécies em diâmetro à altura do solo - DAS}

As espécies que mais se destacaram em DAS foram C. gongonha (laranjeira-do-brejo), C. odorata (cedro-do-brejo), A. glandulosa (tapiá) e E. falcata (moxoco), conforme a Figura 7.

As espécies que obtiveram valores intermediários do valor do DAS foram $T$. americana (pau-formiga), A. polyphylla (monjoleiro) e C. urucurana (sangra-d'água), esta, segundo Maximiano (2008), obteve destaque em DAS em seu estudo de avaliação de espécies florestais no entorno de uma nascente pontual em Inconfidentes, MG, significando que a espécie se desenvolve bem em DAS em áreas de solos drenados.

As espécies que obtiveram baixo desenvolvimento em DAS foram I. vera (ingá), C. ecalyculata (café-de-bugre) e N. nitidula (canelinha).

Figura 7. Desenvolvimento das espécies em DAS ao longo das onze avaliações.

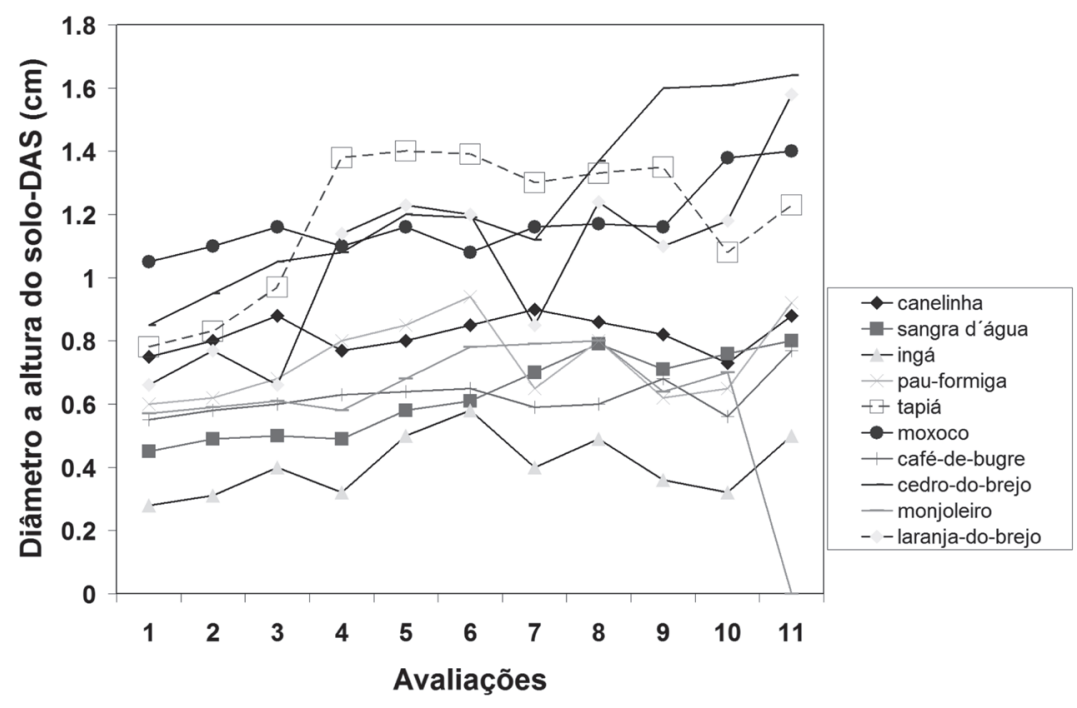

Fonte: Elaboração própria. 


\subsection{Desenvolvimento das espécies plantadas em diâmetro de copa}

De acordo com a Figura 8, as espécies que mais se desenvolveram em diâmetro de copa foram E. falcata (moxoco), A. glandulosa (tapiá), C. gongonha (laranjeira-do-brejo), C. odorata (cedro-do-brejo). De acordo com Maximiano (2008), as espécies E. falcata (moxoco), C. gongonha (laranjeira-do-brejo) e $C$. odorata (cedro-do-brejo) foram as que se destacaram em diâmetro de copa em seu estudo de avaliação do desenvolvimento de espécies florestais no entorno de uma nascente pontual em Inconfidentes, MG.

As espécies que obtiveram médio desenvolvimento em diâmetro de copa foram $C$. ecalyculata (café-de-bugre), N. nitidula (canelinha) e C. urucurana (sangra-d'água).

As espécies que não obtiveram bom desenvolvimento em diâmetro de copa foram A. polyphylla (monjoleiro) e T. americana (pau-formiga).

Figura 8. Desenvolvimento das espécies em Diâmetro de Copa ao longo das onze avaliações.

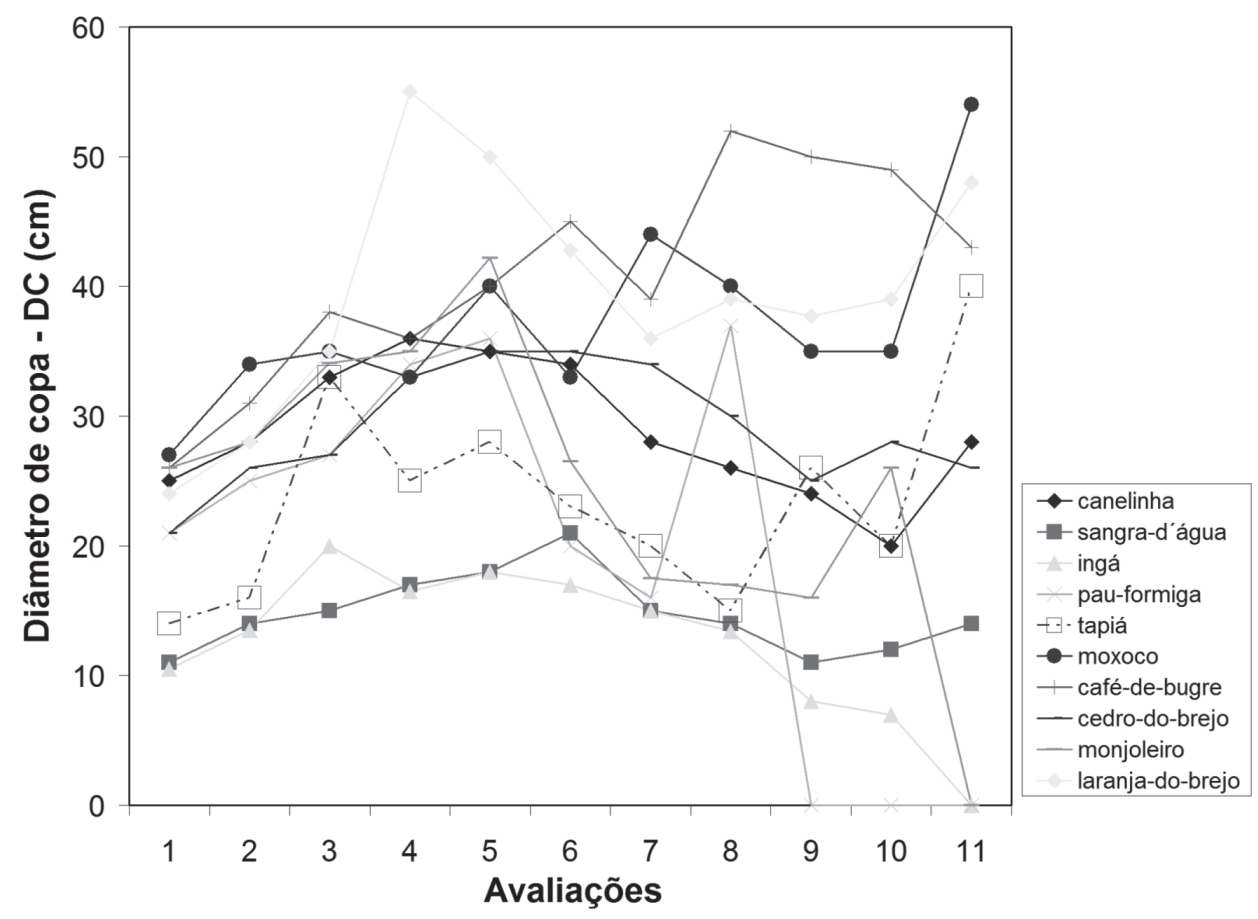

Fonte: Elaboração própria.

\subsection{Desenvolvimento das espécies plantadas em Altura, DAS e Diâmetro de Copa}

As espécies plantadas no experimento que se desenvolveram melhor nos três parâmetros morfológicos (Altura, DAS e Diâmetro de Copa) foram C. gongonha (laranjeira-do-brejo) e C. odorata (cedro-do-brejo).

As espécies $E$. falcata (moxoco) e A. glandulosa (tapiá) obtiveram destaque em duas das variáveis em estudo (DAS e Diâmetro de Copa).

A espécie C. urucurana (sangra-d'água) obteve destaque em uma das variáveis em estudo (Altura).

Segundo Torres et al. (1992) e Toniato et al. (1998), as matas de brejo contém um número relativamente menor de espécies do que as outras, isto explica porque somente duas espécies se 
desenvolveram melhor nessa área. Segundo Joly (1991), poucas espécies desenvolvem adaptações que possibilitam sua sobrevivência em ambientes alagados.

\section{Conclusão}

Das espécies plantadas na área paludosa e avaliadas durante onze meses, as que apresentaram melhor desenvolvimento em altura foram: Citronella gongonha (laranjeira-do-brejo), Cedrela odorata (cedro-do-brejo) e a Croton urucurana (sangra-d'água). As espécies que apresentaram melhor desenvolvimento em DAS foram Citronella gongonha (laranjeira-do-brejo), Cedrela odorata (cedro-do-brejo), Alchornea glandulosa (tapiá) e Erythrina falcata (moxoco). As espécies que apresentaram melhor desenvolvimento em Diâmetro de Copa foram Erythrina falcata (moxoco), Alchornea glandulosa (tapiá), Citronella gongonha (laranjeira-do-brejo) e Cedrela odorata (cedro-do-brejo).

Houve alta taxa de mortalidade (52\%) dos indivíduos em área paludosa, concluindo que poucas espécies apresentaram capacidade de sucesso em plantios nestas áreas.

0 resultado deste trabalho pode servir de subsídio a outros trabalhos, como os de recuperação de áreas paludosas, áreas ciliares, zonas ripárias entre outros correlacionados a plantio de espécies tolerantes a encharcamento temporário e permanente.

\section{Evaluation of the development of native plants in a swampy area in Inconfidentes municipality, MG}

\section{Abstract}

This paper deals with the initial evaluation of the development of a hundred native plants, for eleven months, planted in a swampy area in the experimental farm of the Instituto Federal de Educação Ciência e Tecnologia do Sul de Minas Gerais (Federal Institute of Science Education and Technology of South of Minas Gerais), Inconfidentes campus, MG. The ten native species chosen for planting were Nectandra nitidula (shin), Croton urucurana (bleed-d'água), Inga vera (inga), Triplaris americana (wood-ant), Alchornea glandulosa (tapiá), Erythrina falcata (moxoco), Cordia ecalyculata (coffee-of-Indian), Cedrela odorata (cedar-pity-swamp), Acacia polyphylla (monjoleiro) and Citronella gongonha (orange tree-pity-swamp). Ten plants of each species were planted within a space of $1.5 \times 2.0 \mathrm{~m}$, in September 2007. Evaluations were monthly made until the month of July 2008 . The parameters used in the evaluations were: height $(\mathrm{H})$, diameter at soil height (DAS) and Treetop Diameter. In the eleven assessments, these parameters showed that the species had different rates of development, depending on the area to be permanently drenched. Species that have excelled in height, DAS and treetop diameter were Citronella gongonha (laranjeira-do-brejo) and Cedrela odorata (cedro-do-brejo), meaning that these species are the most conducive for paludoso environment.

Keywords: Marsh. Plant growth. Hydrophilic species. 


\section{Referências bibliográficas}

ARAÚJO, M. M. et al. Análise de Agrupamento da Vegetação de um Fragmento de Floresta Estacional Decidual Aluvial, Cachoeira do Sul, RS, Brasil. Ciência Florestal, Santa Maria, v.14, n.1, p.133-147, 2004.

ARAÚJO, S. M. V. G. de. As Áreas de Preservação Permanente e a Questão Urbana: estudo técnico de consultoria legislativa da área de meio ambiente, direito ambiental, organização territorial, desenvolvimento urbano e regional. Brasília: [s.n.], 2002. 12p.

BOTELHO, S.A.; DAVIDE, A.C. Métodos Silviculturais para Recuperação de Nascentes e Recomposição de Matas Ciliares. In: SIMPÓSIO NACIONAL SOBRE RECUPERAÇÃO DE ÁREAS DEGRADADAS, 2002, Belo Horizonte. Anais... Belo Horizonte, [s.n.], 2002. p123-145.

BRASIL, Lei n. 12.651, 25 de maio de 2012. Revoga a Lei n. 4.771, 15 de setembro de 1965, do novo Código Florestal. Disponível em: < http://www.planalto.gov.br/ccivil_03/_Ato20112014/2012/Lei/L12651.htm>. Acesso em: 25 abr. 2013.

BUDKE, J. C. et al. Florística e Fitossociologia do Componente Arbóreo de uma Floresta Ribeirinha, Arroio Passo das Tropas, Santa Maria, RS, Brasil. Acta Botânica Brasílica, Feira de Santana, v.18, n.3, p.581-589, 2004. Disponível em: <http://www.scielo.br/pdf/abb/v18n3/v18n3a16.pdf > Acesso em: 11 abr. 2013.

CALHEIROS, R. O. et al.(Org). Preservação e Recuperação das Nascentes (de água e de vida). 1. ed. Piracicaba: Comitê das Bacias Hidrográficas dos Rios Piracicaba, Capivari e Jundiaí (CBH-PCJ), 2004. 53p.

CARBONARI, C.A.; MARTINS, D.; TERRA, M.A. Controle de Brachiaria subquadripara e Brachiaria mutica através de diferentes herbicidas aplicados em pós-emergência. Planta daninha. Viçosa, v. 21, n. spe, p. 79-84, 2003. ISSN 0100-8358. Disponível em: <http://dx.doi.org/10.1590/ S0100-83582003000400011 >. Acesso em: 11 abr. 2013

CASTRO, P.S.; GOMES, M. A. Técnicas de Conservação de Nascentes. Ação Ambiental, Viçosa, v. 4, n. 20, p. 24-26, out./nov. 2001.

CASTRO, P. S. Bacias de cabeceira: Verdadeiras Caixas d' água da Natureza. Ação Ambiental, Viçosa, v. 1, n. 3, p. 9-11, dez./jan. 1999.

CESP - COMPANHIA ENERGÉTICA DE SÃO PAULO. Considerações sobre as matas ciliares e a implantação de reflorestamento misto nas margens de rios e reservatórios. CESP, São Paulo, 1987.

CIELO FILHO, R.; SANTIN, D. A. Estudo Florístico e Fitossociológico de uma Fragmento Florestal Urbano - Bosque dos Alemães, Campinas, SP. Revista Brasileira de Botânica,São Paulo, v.25, n.3, p.291-301, 2002.

CRUZ, J. E. et al.. Projeto Ribeirão da Cachoeira em Espírito Santo do Pinhal, SP. Revista Ecossistema, Espírito Santo do Pinhal, v.27, n.1,2, p.17-22, 2003. 
DAVIDE, A.C.; BOTELHO, S. A. Análise crítica dos programas de recomposição de matas ciliares em Minas Gerais. In: SIMPÓSIO MATA CILIAR: CIÊNCIA E TECNOLOGIA, Belo Horizonte, 1999. Anais... Lavras: UFLA/FAEPE/CEMIG, 1999. p.172-188.

DAVIDE, A.C. et al. Comportamento de Espécies Florestais de Mata Ciliar em Áreas de Depleção do Reservatório da Usina Hidrelétrica de Camargos, Itutinga, MG. Revista Cerne, Lavras, v.2, n.1, p.20-34, 1996.

FERREIRA, M. J.; FERREIRA, W. C.; BOTELHO, S. A. Avaliação da Regeneração Natural do Entorno de uma Nascente como Estratégia para sua Recuperação. Revista Brasileira de Biociências, Porto Alegre, v.5, n.1, p.573-575, 2007b.

FERREIRA, W. C. et al. Avaliação do Crescimento do Extrato Arbóreo de Área Degradada Revegetada à Margem do Rio Grande, na Usina Hidrelétrica de Camargos, MG. Revista Árvore, Viçosa, MG, v.31, n.1, p.177-185, 2007a.

GOMES, E. P. C.; FISCH, S. T. V.; MANTOVANI, W. Estrutura e Composição do Componente Arbóreo na Reserva Ecológica do Trabiju, Pindamonhangaba, SP, Brasil. Acta Botânica Brasílica, Feira de Santana, v.19, n.3, p.451-464, 2005. Disponível em: <http://www.scielo.br/scielo. php?script=sci_arttext\&pid=S0102-.33062005000300005>. Acesso em: 11 abr. 2013.

HARDT, E. et al. Plantios de Restauração de Matas Ciliares em Minerações de Areia da Bacia do Rio Corumbataí: Eficácia na Recuperação da Biodiversidade. Scientia Florestalis, Piracicaba, n.70, p.107-123, 2006. Disponível em: <http://www.ipef.br/publicacoes/scientia/nr70/cap11.pdf>. Acesso em: 11 Abr. 2013.

Inconfidentes. Clima da cidade de Inconfidentes, 2007. Disponível em: <http://www. inconfidentes.mg.gov.br/cidade.php?codigo=2>. Acesso em: 23 set. 2012.

IVANAUSKAS, N.M.; RODRIGUES, R.R.; NAVE, A.G. Aspectos ecológicos de um trecho de floresta de brejo em Itatinga, SP: florística, fitossociologia e seletividade de espécies. Revista Brasileira de Botânica, São Paulo, v. 20, n.2, p. 139-153, 1997. Disponível em: <http://www.scielo.br/scielo. php?pid=S0100-84041997000200005\&script=sci_arttext > . Acesso em: 11 abr. 2013

JOLY, A. B. Flooding tolerance in tropical trees. In JACSONS M. B.; DAVIS, D. D.; LAMBERS, H. (Ed) Plant life under oxygen deprivation: ecology, physiology and biochemistry. The Hague: SPB Academic Publishing, 1991, p. 23-43.

KÖPPEN, W. 1948. Climatologia. México, Buenos Aires. Ed. Fundo de Cultura Econômica.

LADSLAU, S. Recuperação de Nascentes. Disponível em: < http://www.todafruta.com.br/todafruta/ mostra_conteudo.asp?conteudo=14845>. Acesso em: 23 set. 2012.

LEITÃO FILHO, H. F. Aspectos taxonômicos das florestas do Estado de São Paulo. In: Congresso Nacional sobre Essências Nativas. Campos do Jordão, 1982. Anais... Campos do Jordão: Instituto Florestal, 1982, p. 197-206.LIEBERG, S. A.; JOLY, C. A. Inga affinis DC (Mimosaceae): germinação e tolerância de plântulas à submersão. Revista Brasileira de Botânica, São Paulo, v.16, p.175-179, 1993. 
LOBO, D.; LEÃO, T.; TABARELLI, M., Espécies indicadas para Recuperação de áreas Degradadas na Região da Floresta Atlântica ao Norte do Rio São Francisco. Recife: CEPAN, 2007.

LOBO, P. C.; JOLY, C. A. Tolerance to hypoxia and anoxia in neotropical tree species. Pp. 137-156. In F. R. Scarano \& A. C. Franco (ed.). Ecophysiological strategies of xerophytic and amphibious plants in the neotropics. Series Oecologia Brasiliensis. vol IV. PPGE-UFRJ, Rio de Janeiro, 1998.

LOBO-FARIA, P. C. Estratégias adaptativas de espécies arbóreas típicas de ambiente com solo hidricamente saturado: uma abordagem morfológica, bioquímica e ecofisiológica. 1998. Tese (Doutorado). Universidade Estadual de Campinas, Campinas.

LORENZI, H. Árvores Brasileiras, Manual de Identificação e Cultivo de Plantas Arbóreas Nativas do Brasil. Nova Odessa: Instituto Plantarum, 2002.

LOURES, L. Variações Florísticas e Estruturais em um fragmento de floresta paludosa, no Alto Rio Pardo, em Santa Rita de Caldas, MG. 2006. Dissertação (Mestrado). Universidade Federal de Lavras, Lavras.

LOURES, L. Et al. Florística, Estrutura e Características do Solo de um Fragmento de Floresta Paludosa no Sudeste do Brasil. Acta Botanica Brasílica, São Paulo, v.21, n.4, p.885-896, 2007. Disponível em: <http://www.scielo.br/scielo.php?script=sci_arttext\&pid=S010233062007000400013\&lng=en\&nrm=iso\&tlng=pt>. Acesso em: 15 abr. 2012.

MARQUES, M. C. M.; JOLY, C. A. Germinação e Crescimento de Calophyllum brasiliense Camb. (Clusiaceae), uma Espécie típica de Florestas Inundadas. Acta Botanica Brasílica, Feira de Santana, v.14, n.1, p.133-120, 2000. Disponível em:<http://www.scielo.br/pdf/abb/v14n1/ v14n1a10.pdf>. Acesso em: 15 abr. 2013

MARQUES, M. C. M. Estudos auto-ecológicos do guanandi (Calophyllum brasiliense Camb. CLUSIACEAE) em mata ciliar no município de Brotas, SP. 1994. 91 f. Dissertação (Mestrado). Universidade de Campinas, Campinas. Disponível em: < http://www.bibliotecadigital.unicamp.br/ document/?code =vtls000075158> . Acesso em: 15 Abr. 2013

MARQUES, M. C. M.; Silva, S. M.; Salino, A., Florística e Estrutura do Componente ArbustivoArbóreo de uma Floresta Higrófila da Bacia do Rio Jacaré-Pepira, SP, Brasil. Acta Botanica Brasílica, São Paulo, v.17, n.4, p.495-506, 2003. Disponível em: <http://www.scielo.br/scielo. php? pid =S0102-33062003000400002\&script=sci_arttext > . Acesso em: 15 abr. 2013

MAXIMIANO, N. A., Avaliação do Crescimento Inicial de Vinte e Nove Espécies Florestais no Entorno de uma Nascente Pontual em Processo de Recuperação. 2008. 58 f. Graduação (Monografia). Escola Agrotécnica Federal de Inconfidentes, EAFI, Inconfidentes.

MEYER, S. T. et al. Composição Florística da Vegetação Arbórea de um Trecho de Floresta de Galeria do Parque Estadual do Rola-Moça na Região Metropolitana de Belo Horizonte, MG, Brasil. Acta Botânica Brasílica, São Paulo, v.18, n.4, p.701-709, 2004.

MORAIS, M. G. A. de. Diversidade e Estrutura de Nove Fragmentos de Mata Ciliar Semidecidual no Alto São Francisco. Revista Brasileira de Biociências, Porto Alegre, v.5, supl.2, p.543-545, 2007. Disponível em: <http://www.ufrgs.br/seerbio/ojs/index.php/rbb/article/view/477/419>. Acesso em: 15 abr. 2013 
OLIVEIRA FILHO, A. T. Estudos ecológicos da vegetação como subsídios para programas de revegetação com espécies nativas: uma proposta metodológica. Cerne, Lavras, v. 1, n. 1, p. 64-72, 1994.

PIMENTA, J. A.; BIANCHINI, E.; MEDRI, M. E. Adaptations to flooding by tropical trees: morphological and anatomical modifications. Pp. 157-176. In F. R. Scarano \& A. C. Franco (ed.). Ecophysiological strategies of xerophytic and amphibious plants in the neotropics. Series Oecologia Brasiliensis. v. 4. PPGE-UFRJ, Rio de Janeiro, 1998.

PINTO, L. V. A. Distribuição das Espécies Arbóreo-Arbustivas ao longo do Gradiente de Umidade do Solo de Nascentes Pontuais da Bacia Hidrografia do Ribeirão Santa Cruz, Lavras,MG. Cerne, Lavras, v.11, n.3, p. 294-305, 2005.

REDFORD, K. H.; FONSECA, G. A. B.. The role of gallery forests in the zoogeography of the cerrado's non-volant mamalian fauna. Biotropica, [s.I], 18:126-135, 1986. Disponível em: <http://si-pddr.si.edu/jspui/bitstream/10088/4237/1/Redford1986a.pdf> .Acesso em: 15 Abr. 2013

ROCHA, C. T. V. Comunidade Arbórea de um continuum entre Floresta Paludosa e de Encosta em Coqueiral, Minas Gerais, Brasil. Revista Brasileira de Botânica, São Paulo v.28, n.2, p.203-218, 2005. Disponível em: <http://www.scielo.br/scielo.php?pid=S0100$84042005000200002 \&$ script=sci_arttext>. Acesso em: 15 Abr. 2013

RODRIGUES, L.A. Florística e Estrutura da Comunidade arbórea de um Fragmento Florestal em Luminárias, MG, Acta Botânica Brasílica, São Paulo, v.17, n.1, 71-87, 2003. Disponível em: $<$ http://www.scielo.br/scielo.php?script=sci_arttext\&pid=S0102-33062003000100006 >. Acesso em: 15 Abr. 2013

RODRIGUES, R.R.; NAVE, A.G. Heterogeneidade florística das matas ciliares. In RODRIGUES, R. R.; LEITÃO-FILHO, H. F. (ed.). Matas ciliares: conservação e recuperação. São Paulo:EDUSP/ FAPESP, p.45-71, 2000.

SILVA, A. C. da, Diversidade e Estrutura de Espécies Arbóreas e Relações com Variáveis Ambientais em Fragmentos de Floresta Aluvial em São Sebastião da Bela Vista, Minas Gerais. In: Variações do Componente Arbóreo de Fragmento de Floresta Aluvial do Médio Sapucaí, Minas Gerais, e Padrões Fitogeográficos de Florestas Inundáveis. 2007. 117f. Tese (Doutorado). Universidade Federal de Lavras, Lavras.

SOARES, V. P. et al. Avaliação de Áreas de uso Indevido da Terra em uma Microbacia no Município de Viçosa-MG, Através de Fotografias Aéreas e Sistema de Informação Geográfica. Revista Árvore, Viçosa, v.26, n.2, p.243-251, 2002.

SOUZA, V. C.; LORENZI, H., Botânica Sistemática: Guia Ilustrado para identificação das famílias de Angiospermas da flora brasileira, baseado em APG II. Instituto Plantarum, Nova Odessa, 2005.

TEIXEIRA, A. P.; ASSIS, M. A. Caracterização Florística e fitossociológica do Componente ArbustivoArbóreo de uma Floresta Paludosa no Município de Rio Claro (SP), Brasil. Revista Brasileira de Botânica, São Paulo, v.28, n.3, p.467-476, 2005. Disponível em: <http://www.scielo.br/scielo. php?pid=S0100-84042005000300005\&script=sci_arttext>. Acesso em: 15 Abr. 2013 
TONIATO, M. T. Z.; LEITÃO-FILHO, H. de F.; RODRIGUES, R. R., Fitossociologia de um remanescente de floresta higrófila (mata de brejo) em Campinas, SP. Revista Brasileira de Botânica, São Paulo, v.21 n. 2, 1998.

TORRES, R. B. et al. Espécies florestais nativas para plantio em áreas de brejo. 0 Agronômico, Campinas, v.44, n.1/3, p.13-16, 1992.

VELOSO, H. P.; RANGEL FILHO, A. L.; LIMA, J. C. A.Classificaçao da vegetação brasileira, adaptada a um sistema universal. Rio de Janeiro IBGE, Departamento de Recursos Naturais e Estudos Ambientais, 1991 . 124 p. Disponível em: <http://biblioteca.ibge.gov.br/visualizacao/ monografias/GEBIS\%20-\%20RJ/classificacaovegetal.pdf>.Acesso em: 15 abr. 2013

VILELA, E. A. et al. Caracterização Estrutural de Floresta Ripária do Alto Rio Grande, em Madre de Deus de Minas, MG. Cerne, Lavras, v.6, n.2, p.41-54, 2000.

\section{Histórico editorial}

Recebido: 05/10/2012

Avaliação e copidesque: 17/10/2012 a 25/01/2013 


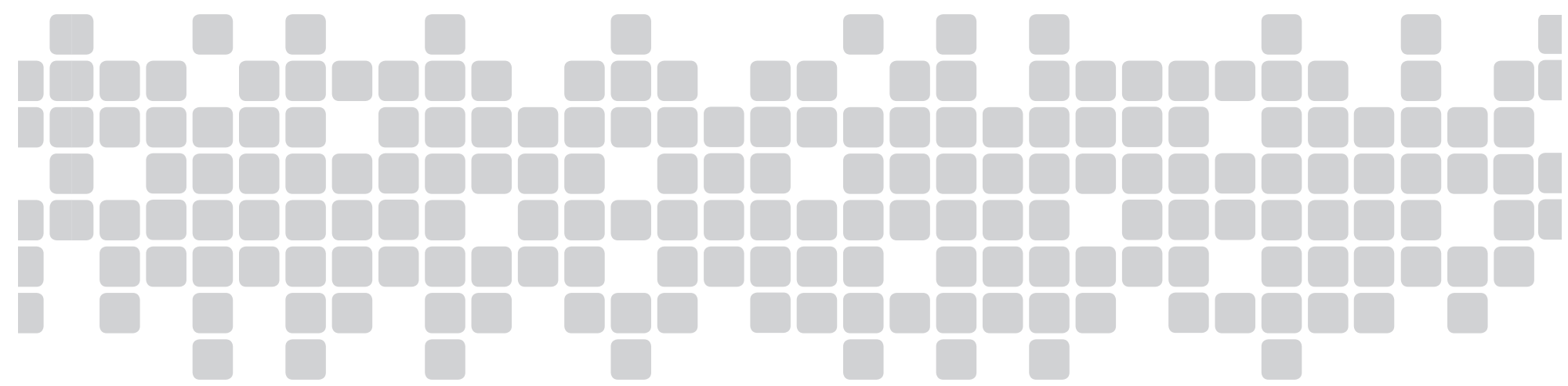

